\title{
Canine separation anxiety: strategies for treatment and management
}

This article was published in the following Dove Press journal:

Veterinary Medicine: Research and Reports

30 October 2014

Number of times this article has been viewed

\section{Rebecca J Sargisson}

School of Psychology, University of Waikato, Tauranga, New Zealand
Correspondence: Rebecca J Sargisson School of Psychology, University of Waikato, Private Bag 12027, Tauranga 3। 12, New Zealand

Email sargisson@waikato.ac.nz
Abstract: Dogs with separation-related behavior problems engage in unwanted behavior such as destruction of property and excessive vocalization when left alone, causing distress for both the dog and the owner, and often leading to the dog being relinquished or euthanized. I review research on factors likely to predispose dogs to developing separation anxiety and on the treatments available. Although research is equivocal, dogs seem to develop separation-related behavior problems if they are male, sourced from shelters or found, and separated from the litter before they are 60 days old. Protective factors include ensuring a wide range of experiences outside the home and with other people, between the ages of 5-10 months, stable household routines and absences from the dog, and the avoidance of punishment. The most successful treatment for canine separation-related problems may be behavior modification that focuses on systematic desensitization and counterconditioning, which can be supplemented with medication in the initial stages. Where individual therapy from an animal behavior expert is not possible, advice to dog owners should be clear, simple, and contain five or fewer instructions to improve adherence. Advice is given for people seeking to adopt a dog, for new dog owners, and for existing dog owners who wish to treat their dog's separation anxiety.

Keywords: systematic desensitization, counterconditioning, medication, separation anxiety

\section{Introduction}

Dogs without separation-related behavior problems are passive and inactive in their owner's absence, ${ }^{1,2}$ and the initially anxious behavior of puppies separated from their owners ${ }^{3}$ has been found to decrease quickly after adoption. ${ }^{4}$ Dogs with separationrelated behavior problems, in contrast, engage in undesirable behaviors when left alone. The most common of these are destruction and excessive vocalization, including whining and barking. ${ }^{5-9}$ Less common problem behaviors include inappropriate elimination (urination and defecation), self-injurious behavior (eg, over-grooming), increased or repetitive motor activity (eg, pacing), attempts to escape, trembling, salivation, and depression. ${ }^{10,11}$

The bond formed between dogs and their human owners is consistent with an attachment. ${ }^{12}$ The emotional attachment between adult dogs and their owners, even in the absence of separation-related behavior problems, has been found to be similar to that displayed by human adults and their children. ${ }^{13}$ This is not surprising given that dogs have been selected for their dependence on humans over 10,000 or more years of domestication. ${ }^{13}$

While most dogs are emotionally attached to their owners, anxious dogs exhibit more attachment behaviors than dogs that are less anxious. ${ }^{13}$ Separation anxiety has 
been defined as distress in the absence of an attachment figure. ${ }^{14}$ In addition to performing unwanted behaviors in the owner's absence, dogs with separation-related problems will often show signs of excessive attachment to their owners. ${ }^{15}$ For example, dogs may follow their owners around when they are home, and when their owners are preparing to leave the house. ${ }^{6,15}$ Some dogs will begin to whine, pace, pant, or freeze as their owner's departure becomes imminent. ${ }^{15}$

If the rate or intensity of separation-related behaviors increased across the separation period, we might hypothesize that the dog was bored. ${ }^{16}$ Instead, the peak intensity of separation-related behaviors occurs shortly after the owner's departure. ${ }^{16}$ Dogs with separation-related problems also tend to engage in excessive excitement when the owner returns. ${ }^{6,15}$

However, while some researchers have provided evidence to suggest that dogs with separation-related problems are excessively attached to their owners, ${ }^{6,15}$ other research contradicts this finding. ${ }^{17}$ Parthasarathy and Crowell-Davis ${ }^{18}$ found that dogs spent the same amount of time in close proximity to their owners in an attachment test, regardless of their scores on a test of separation anxiety, suggesting that the time spent close to the owner would not be a useful diagnostic indicator of a separation-related problem. Stephen and Ledger ${ }^{19}$ found high significant correlations between ratings of separation anxiety given by dog owners who relinquished their dogs to shelters and ratings given by the dogs' new owners, suggesting that it is not attachment to particular humans that is problematic for these dogs, but a problem that the dog takes with them to new contexts. In fact, the correlation between ratings given by new and former owners for separation anxiety was higher than for any other reported canine problem. Stephen and Ledger's ${ }^{19}$ findings suggest that dogs who have not received treatment for separation-related problems are unlikely to improve when rehomed.

\section{Importance of separation-related problems}

The incidence of separation-related behavior problems has been estimated at $20 \%$ of the dog population. ${ }^{20}$ However, diagnosis of a canine separation-related problem generally relies on indirect evidence, such as evidence of destruction or reports of barking by neighbors, because the problem behaviors occur primarily in the absence of the owner. ${ }^{10}$ The reliance on indirect evidence may lead to under-reporting and under-diagnosis. ${ }^{11,20}$

When left alone, dogs can cause much damage to a home, and injure themselves in the process. Overall ${ }^{21}$ described a dog who destroyed drywall, tile, and insulation in a home. This dog tore its tongue, broke teeth, and suffered cuts to its face and feet. A dog with separation-related problems in a study by Gaultier et $\mathrm{al}^{7}$ ate part of the home electricity supply, setting fire to the house in its owners' absence. Dogs that engage in excessive vocalization when left alone are likely to prompt complaints by neighbors and visits from local authorities. Sherman and Mills ${ }^{22}$ note that living with a dog with separation-related problems causes emotional and financial distress in the home, which can lead to the surrendering of the dog. Indeed, separation-related problem behaviors are commonly cited reasons for relinquishing dogs to animal shelters. ${ }^{23,24}$ Although separation-related problems seem to appear at a similar age as aggressive behaviors, owners wait longer before seeking help with canine separation-related problems. $^{25}$

Separation anxiety is associated with a higher incidence of, and more severe, skin problems for dogs. ${ }^{26}$ Dogs with separation-related problems are also likely to exhibit anxious behavior in response to loud noises such as fireworks and thunderstorms, ${ }^{27}$ although this may only be the case for clinical populations with well-established problems. ${ }^{28}$ Dogs with anxiety-related disorders, in general, are more likely to be aggressive toward their owners or strangers and to engage in phobic or compulsive behaviors. ${ }^{29}$

\section{Factors that predispose dogs to separation-related behavior problems}

Researchers investigating the factors that predispose dogs to developing separation anxiety have found contradictory results. Most researchers have found that dogs with anxietyrelated problems are more likely to be male, ${ }^{6,14,17,25,30-33}$ but some research has not supported any sex difference in the incidence of separation-related problem behaviors. ${ }^{11,34}$

Similarly, some researchers have found that dogs are more likely to develop separation-related problems if they sleep on the owner's bed or sofa, ${ }^{29}$ while others have not found the same result. ${ }^{6,9,35}$ Some researchers have found no link between the source of dog acquisition and the presence of separation-related problems, ${ }^{11}$ and they report that dogs obtained from breeders are just as likely as dogs sourced elsewhere to develop separation-related problems. ${ }^{29}$ Other researchers report that dogs obtained from animal shelters, or those that are found, are more likely to develop separationrelated problems, ${ }^{6,29,35}$ and that dogs obtained from friends and family have a lower incidence of separation-related problems. $^{17}$ 
Higher rates of separation-related behavior problems have been reported for dogs that live with a single adult, ${ }^{6}$ a couple, ${ }^{29}$ or multiple adults ${ }^{6}$ than for those dogs that live with a family with children, but other researchers have found that the presence or absence of children in the home had no effect on the prevalence of separation-related problems. ${ }^{9}$ Some researchers have found an increased probability of separation-related problems with increasing numbers of adult women in the home, ${ }^{9,17}$ whereas other researchers have found no link between sex of the owner and the incidence of a dog's separation anxiety. ${ }^{6}$

Researchers have found that dogs that have food at their disposal rather than delivered at discrete times ${ }^{29}$ and those dogs that are adopted when they are older, ${ }^{25,29}$ are more likely to develop separation-related problems. There is evidence of high rates of separation-related problems among dogs who live in apartments, ${ }^{9}$ and the incidence of separation-related problems of apartment dogs is higher than their incidence of aggression. ${ }^{25}$

Dogs exposed to humans outside the home, and to a wide range of experiences between the age of 5-10 months are less likely to develop separation-related problems. ${ }^{30}$ Some evidence exists to suggest that dogs that are separated from the litter early (less than 60 days) are more likely to develop problem behaviors, including destructive behavior and excessive vocalization, ${ }^{36}$ particularly if those dogs are sourced from pet shops.

There is some evidence that canine separation anxiety can be triggered or exacerbated by a change in the household such as a new human resident, a job change, ${ }^{17,37}$ a change in the routine of owner's absences from the home, ${ }^{38}$ or a single traumatic event. ${ }^{38}$ For example, the separation-related problems of a dog in Butler et al's ${ }^{38}$ study may have been exacerbated when the dog was left for 8 hours alone in a bathroom that flooded with hot water. Another dog's problems began after it was left tied up in a laundry room by its caregivers for 2 weeks while the owners were away. However, other researchers have not found a link between the onset of separation anxiety and a household change. ${ }^{6}$

To summarize, there are several contributors to the development of canine separation anxiety. Male dogs are more frequently found to demonstrate such problems than female dogs. ${ }^{6,14,17,25,30-33}$ Separations from the litter at a young age, particularly for dogs sourced from pet shops ${ }^{36}$ a lack of experience outside the home for puppies aged 5-10 months, ${ }^{30}$ and late age at adoption ${ }^{25,29}$ are also risk factors. Dogs sourced from animal shelters or those that are found $\mathrm{d}^{6,29,35}$ may be more likely to display separation anxiety than those sourced from breeders or friends and family. Dogs residing in apartments ${ }^{9,25}$ and in homes with no human children ${ }^{6,29}$ are also at higher risk. Separation-related problems may be triggered or exacerbated by a change in household circumstances such as the addition of a family member or a change in routine. ${ }^{17,37,38}$

There is also some evidence that dogs who are excessively attached to their owners are more likely to develop separation anxiety ${ }^{6,15}$ and that anxious dogs generally display more attachment behaviors. ${ }^{13}$ Thus, dogs who are allowed to follow their owners from room to room, who are encouraged to display more overt leaving and greeting behavior, and who are excessively bonded to their owners may be more anxious in their owner's absence.

\section{Treatments for canine separation anxiety}

It has been suggested that adding another animal, such as another dog, to the household may help dogs with separationrelated behavior problems to cope with absences from their owner. ${ }^{38,39}$ However, evidence suggests that the presence of another dog in the household does not prevent another dog from developing separation-related problems., ${ }^{9,11,14}$

Owners may respond to the separation-related problem behaviors of their dogs by confining the dog to a crate. Some authors have recommended this approach because once the dog is accustomed to the crate they rarely engage in the stressrelated behaviors exhibited by dogs that have free access during periods of separation from their owner. ${ }^{40}$ However, others have found that dogs left in crates or cages while at home alone are no less likely to display separation-related problem behaviors than dogs that have free access to the home. ${ }^{14}$ In fact, confining a dog with separation anxiety to a crate can increase lip licking, ${ }^{11}$ a response consistent with stress, ${ }^{41}$ and dogs can injure themselves in attempts to escape from the crate. ${ }^{39}$

Dog owners who return to a house subjected to destruction may punish the dog. However, high frequencies of punishment are associated with anxious behavior for small dogs and dogs are less anxious when a high proportion of their training interactions involve positive reinforcement. ${ }^{42}$ Additionally, punishment delivered upon the owner's return to the house is unlikely to be temporally contingent upon the problem behavior and is likely, therefore, to be ineffective. ${ }^{43,44}$ Thus, punishment is best avoided in dealing with dogs with separation-related problems. ${ }^{20,43}$

\section{Medications}

Two pharmacological interventions clomipramine $\left(\right.$ Clomicalm $\left.^{\circledR}\right)$ and fluoxetine $\left(\right.$ Prozac $\left.^{\circledR}\right)$ are approved in the 
United States for the treatment of canine separation anxiety. ${ }^{45}$ These are antidepressant drugs used for humans to treat the symptoms of depression and anxiety.

At a dose of $1 \mathrm{mg} / \mathrm{kg}$ every 12 hours, clomipramine increases passive behavior and decreases pacing, scratching, and whining of dogs with separation anxiety in the absence of their owners. ${ }^{45}$ Improvements in symptoms of separation-related problem behavior following standard doses of clomipramine of $1 \mathrm{mg} / \mathrm{kg}$ to $<2 \mathrm{mg} / \mathrm{kg}$ every 12 hours have been reported..$^{31,45}$ Increasing the dose to $2 \mathrm{mg} /$ $\mathrm{kg}$ every 12 hours produces additional increases in the time the dogs are passive and reduces barking and whining when dogs are left alone. ${ }^{45}$

Some researchers have investigated whether the effectiveness of clomipramine or fluoxetine can be enhanced when they are combined with other medications. Ogata and Dodman ${ }^{46}$ studied the effect of the concurrent administration of clonidine, a drug used for humans to reduce high blood pressure, with clomipramine. The owners of seven of ten dogs given a low dose of clonidine in addition to their regular clomipramine medication for separation anxiety reported an improvement in their dogs' behavior. ${ }^{46}$ A combination of fluoxetine and clorazepate dipotassium was found to reduce signs of anxiety in nonaggressive dogs; ${ }^{47}$ however, these medications were administered concurrently with a behavior modification plan, which makes it difficult to assess the effectiveness of each component of the treatment.

Chewable fluoxetine tablets, in the absence of behavioral therapy, have been found to improve separation-related problem behaviors of dogs when compared to dogs treated with a placebo. ${ }^{8,48}$ Ibáñez and Anzola ${ }^{49}$ reported large or moderate improvements for $71 \%$ of dogs with separation-related problems when a low dose of fluoxetine $(1 \mathrm{mg} / \mathrm{kg}$ every 24 hours) was combined with oral diazepam $(0.3 \mathrm{mg} / \mathrm{kg}$ every 24 hours) and behavioral advice. However, adverse side effects, such as ataxia, agitation, and increased appetite, are common with diazepam administration. ${ }^{50}$

Cannas et $\mathrm{al}^{45}$ report that clomipramine did not produce any adverse reaction in any dog in their study, but dog owners in other studies have reported unwanted side effects when they have used pharmacological interventions for the treatment of separation anxiety, such as lethargy following the administration of amitriptyline, an antidepressant. ${ }^{33}$ Landsberg et $\mathrm{al}^{48}$ found that $85 \%$, and Simpson et $\mathrm{al}^{8}$ found that $45 \%$ of dogs administered fluoxetine exhibited lethargy or depression, and significantly more dogs who received fluoxetine experienced a loss of appetite than dogs who received a placebo in both studies. Lethargy and vomiting have been associated with clomipramine administration, ${ }^{31}$ which has also been linked to the development of canine pancreatitis, ${ }^{51}$ a condition that presents as abdominal pain, vomiting, and lethargy. Simpson et $\mathrm{al}^{8}$ found that $29.5 \%$ of dogs in their study refused to consume chewable tablets.

Cannas et $\mathrm{al}^{45}$ and King et $\mathrm{al}^{31}$ reported that the administration of clomipramine did not completely eliminate signs of separation anxiety. Additionally, some studies investigating the efficacy of medication to treat separationrelated problems have simultaneously implemented behavior modification, ranging from systematic desensitization and counterconditioning ${ }^{52}$ to more general advice about owner interactions with the dog, ${ }^{31,45,49}$ making it difficult to determine the effect of medication in isolation. Some researchers, however, have found that dogs administered medication concurrently with behavior modification improved more than dogs that received a placebo and behavior modification. ${ }^{8}$ Simpson et $\mathrm{al}^{8}$ found that, among dogs given behavioral therapy, $50 \%$ of those administered a placebo improved compared to $72 \%$ of the dogs administered fluoxetine.

While pharmacological interventions may be useful when used in conjunction with behavior modification, they are unlikely to eliminate a dog's separation-related problem behaviors in isolation, ${ }^{39}$ and some behavioral therapy will still be needed. ${ }^{43,53}$ Appleby and Pluijmakers ${ }^{53}$ recommend drug support in the early phases of interventions for separationrelated problems. Sherman and Mills ${ }^{22}$ note that often owners of dogs with separation-related problems need to reduce the problem behavior quickly, because they are close to making a decision to relinquish or euthanize the dog. These authors recommend medication combined with behavior modification initially, and advise withdrawal of the medication over time. In some instances, Sherman and Mills ${ }^{22}$ suggest that long-term medication might be necessary.

However, other researchers have not found any improvement in separation-related problem behaviors with clomipramine administration when compared to the administration of a placebo. ${ }^{32}$ Rather, Podberscek et al $^{32}$ support the use of behavioral therapy alone. In addition, some dog owners may be reluctant to medicate their dogs or they may find the cost to be prohibitive. ${ }^{33}$

\section{Dog-appeasing pheromone}

Another intervention that has been found to reduce separationrelated behavior is the delivery of a dog-appeasing pheromone using an electric diffuser. Gaultier et $\mathrm{al}^{7}$ found that diffusing the pheromone in the owner's absence was at least as effective as administration of clomipramine, when both were delivered 
with a behavior modification plan, and had fewer undesirable side effects than other medications. ${ }^{7}$ When exposed to the pheromone, $83 \%$ of dogs showed reduced, or eliminated, problem behaviors compared to $70 \%$ of dogs administered clomipramine. The effect of the behavior modification alone was not possible to determine, as both groups of dogs in the study received the same behavioral advice. ${ }^{7}$

\section{Behavioral treatments}

Behavioral advice for separation-related problem behaviors can include reducing the dependency of the dog on the owner, removing punishment for separation-related behaviors, providing activities for the dog to engage in when left alone, and systematic desensitization. Blackwell et $\mathrm{al}^{5}$ found that behavioral advice given to dog owners that included all of these elements was effective in reducing problem behaviors, regardless of the order in which the elements were introduced. There was some suggestion in that study that behavioral interventions developed specifically for individual dogs may have a better chance of success than generic behavioral advice. ${ }^{5}$

Systematic desensitization is a behavioral technique that has been found to be successful in reducing or eliminating the separation-related behavior problems of dogs. ${ }^{38}$ Systematic desensitization is a technique similar to the treatment of phobias of humans (as described by Davison ${ }^{54}$ ) and was developed for use with dogs in the 1960s and 1970s. ${ }^{44}$ It involves exposure to mild versions of the feared stimulus that will not elicit anxiety and subsequent gradual increases in the intensity of the feared stimulus. Initially, the dog is exposed to very short periods of owner absence (it is assumed that this will not elicit anxiety). Because the separation-related problem behaviors begin shortly after the departure of the owner - a latency of 3.25 minutes for vocalization and 7.13 minutes for destruction ${ }^{11}$ - the initial separation period must be short to ensure that the owner's absence is not associated with problem behaviors and, presumably, anxiety. Hence, the owner is advised to leave the dog, initially, for a few seconds, and then to re-enter the house or room and praise the dog. The length of separation is gradually increased until the required period of absence is reached without the reoccurrence of the problem behavior. Presenting short owner absence times repeatedly should ensure that non-anxious behavior will generalize to longer times. Therefore, the time an owner can be absent can be gradually increased until it reaches the duration that elicited the pretreatment separation-related behavior problems, but without causing anxiety. ${ }^{38}$
Systematic desensitization is often used concurrently with counterconditioning, whereby the aversive stimulus is associated with a hedonistic response using classical conditioning techniques. ${ }^{55}$ The concept underlying counterconditioning is that emotional states like anxiety are incompatible with other activities such as relaxation and eating. ${ }^{55}$ Thus, when placed in a situation which usually elicits anxiety, the presentation of food should inhibit the dog's anxiety. ${ }^{55}$ In this way, the previously anxiety-provoking stimulus will become associated with pleasurable states incompatible with anxiety. ${ }^{55}$

A combination of systematic desensitization and counterconditioning for the treatment of fears and phobias of dogs was found to be successful for $100 \%$ of the 91 dogs treated by Rogerson. ${ }^{56}$ The efficacy of systematic desensitization may be greater when it is presented concurrently with counterconditioning than when presented alone. ${ }^{57,58}$ For example, Poppen ${ }^{57}$ demonstrated that significantly fewer trials were required to suppress the conditioned fear of rats when successive presentations of increasing intensity of the fear-inducing stimulus were paired with food delivery than when food delivery, or desensitization, were used in isolation.

Butler et $\mathrm{al}^{38}$ found a program of systematic desensitization and counterconditioning to be an effective treatment for eight dogs with separation-related problem behaviors, even though the treatment was administered by the dog owners and the separation length was inconsistently increased. The same authors note that the separation-related problem behavior was significantly reduced for all dogs in their study, despite the fact that some dog owners failed to implement counterconditioning, or to comply with other behavioral advice. ${ }^{38}$ Their result, therefore, suggests that systematic desensitization is a robust method that can be successfully applied by dog owners.

Systematic desensitization may be preferred by some dog owners because it does not involve medicating the dog and is inexpensive. It does require a commitment by the owner to devote time to resolving the problem. Dog owners have been found to be more noncompliant with instructions that involve a large time commitment, so the success of systematic desensitization relies on the motivation of the owners. ${ }^{33}$ Dog owners should avoid long absences at the beginning of treatment, which may not be an option for all. The primary treatment options and arguments for and against each option are summarized in Table 1.

\section{Other factors that may help}

Recording dog behavior using video cameras mounted in the home can be a useful way of both diagnosing separation-related disorders and of monitoring improvement. ${ }^{42}$ Capturing dog 
Table I Options for the treatment of canine separation-related behavior problems

\begin{tabular}{|c|c|c|}
\hline Treatment & Reasons for use & Reasons against use \\
\hline \multirow[t]{5}{*}{ Medication: general } & Can help to reduce problem behavior & Expensive \\
\hline & May increase efficacy of behavioral interventions ${ }^{8}$ & Medication alone not sufficient to eliminate problem $31,39,45$ \\
\hline & & Medication in the absence of a behavioral intervention \\
\hline & & maintains reliance on medication \\
\hline & & Side effects \\
\hline \multirow[t]{4}{*}{ Medication: clomipramine } & Improvement in separation-related behavior ${ }^{31,45}$ & Side effects: canine pancreatitis; ${ }^{51}$ abdominal pain; \\
\hline & Increases passive behavior ${ }^{45}$ & vomiting; lethargy ${ }^{31}$ \\
\hline & Decreases anxious behavior including pacing, & \\
\hline & scratching, whining, and barking ${ }^{45}$ & \\
\hline \multirow[t]{2}{*}{ Medication: fluoxetine } & Improvements in separation-related behavior $8,48,49$ & Side effects: lethargy, depression, loss of appetite ${ }^{8,48}$ \\
\hline & & Dogs may refuse chewable fluoxetine tablets ${ }^{8}$ \\
\hline \multirow[t]{2}{*}{ Dog-appeasing pheromone } & May reduce problem behavior ${ }^{7}$ & Little research to support use \\
\hline & & Long-term efficacy unknown \\
\hline \multirow[t]{3}{*}{ Systematic desensitization } & Reduces or eliminates problem behavior ${ }^{38}$ & Time-consuming for dog owner \\
\hline & Inexpensive & Need to avoid long absences at the beginning \\
\hline & Does not require medicating the dog & of intervention \\
\hline Counterconditioning & May improve efficacy of systematic desensitization ${ }^{57,58}$ & Probably ineffective in isolation \\
\hline
\end{tabular}

behavior on video can reveal more subtle signs of stress and anxiety, and signs that do not leave physical evidence such as pacing, panting, ${ }^{43}$ mouth licking, body shaking, and stereotyped behavior. ${ }^{41}$

Butler et $\mathrm{al}^{38}$ found that almost all dog owners in their study provided constant companionship to their dogs as a way of "making up" for absences. Sherman and Mills ${ }^{22}$ report that a history of being left alone for long times or experiencing long times with the owner without being left alone are factors associated with canine separation-related problems. These findings suggest that owners should aim for moderation in the length of absences from their dogs.

Herron et $\mathrm{a}^{14}$ investigated the efficacy of behavioral advice to people adopting dogs from shelters in terms of their subsequent report of canine separation-related problems of those adopted dogs. The authors advised exercising the dog prior to a departure, avoiding punishment, and providing a food-stuffed toy during owner absences - none of which prevented canine separation anxiety. However, providing a food-stuffed toy was the only recommendation that was reliably followed by the new dog owners. While providing a food-stuffed toy did not have a significant effect on the incidence of separation-related problem behaviors ${ }^{14}$ this advice was much more specific than the other advice given, perhaps contributing to its adherence rate. The authors advise that to improve their compliance, instructions to dog owners should be clear. Similarly, Takeuchi et a ${ }^{33}$ found that owners who received more than five instructions about how to reduce their dog's separation-related problems were significantly less likely to report improvements in the problem behavior than were owners who received five or fewer instructions. These results suggest that behavioral advice should be clear and that owners should receive as few instructions as possible. Cottam et $\mathrm{al}^{59}$ found no difference between the effectiveness of behavioral advice for canine separation anxiety when it was delivered in person, by phone, or by email, suggesting that the medium by which advice is delivered is unimportant.

\section{Recommendations to dog owners}

Behavioral interventions designed specifically for individual dogs, and therefore that take into account the specific context in which the problem behavior is occurring for each dog, are preferable to generic, nonspecific instructions. ${ }^{5}$ If individualized behavioral intervention is not possible, or if it is financially prohibitive for a dog owner, then the instructions that follow are recommended.

All advice given to dog owners about how to prevent, manage, or treat problematic dog behavior should be clear and specific, ${ }^{14}$ and be limited to no more than five separate instructions. ${ }^{33}$ Thus, instructions should contain the five, or fewer, specific instructions most likely to have a favorable outcome. Instructions are equally effective regardless of whether they are delivered in person or by phone or email $1 .^{59}$ The instructions offered are tailored to three different scenarios: 1) people who are considering owning a dog; 2) new dog owners who wish to prevent separation-related problems; and 3) existing dog owners who wish to treat canine separation-related problems. In each instance, five or fewer, specific instructions, based on the literature presented in this review, have been presented.

\section{For people who are considering owning a dog}

A person seeking to adopt a dog could use selection criteria that minimize the likelihood of canine separation-related 
problems. Dogs least likely to develop such problems appear to be female $e^{6,14,17,25,30-33}$ and sourced from family and friends ${ }^{17}$ rather than from shelters or dogs that are found. ${ }^{6,29,35}$ Adopted dogs should not have been separated from the litter before they are 60 days old, particularly if they are sourced from a pet shop. ${ }^{36}$

\section{Prevention of separation-related problems}

Once the new dog is taken into the house, adhering to the following instructions may help to prevent the development of canine separation-related problems. Provision of a wide range of experiences and human contact outside the home between 5-10 months of age reduces the likelihood of a dog developing separation-related problem behavior. ${ }^{30}$ Dog owners should aim for stability in the dog's routines and in their own absences from the dog, because some evidence shows that sudden changes in household routines and owner-dog interactions can trigger or exacerbate canine separation-related problems. ${ }^{17,37-38}$ Therefore, if the owner must be away for an unusually long time, they should ask a trustworthy person to watch the dog or take the dog with them. Similarly, owners should avoid leaving the dog alone for long times, ${ }^{22}$ but also avoid long periods without leaving the dog alone. ${ }^{22,38}$ Instead, owners should aim for regular absences of short-to-medium lengths from the dog, preferably habituating a newly acquired dog to absences of increasing length by following a systematic desensitization protocol. Finally, dog owners should avoid punishment as a training tool, as the use of punishment increases the chance of producing an anxious dog. ${ }^{42}$ Dog owners should discourage excessive attachment of their dogs to the people in the house by ensuring the dog does not follow them from room to room and by minimizing excitement when leaving or returning to the dog.

\section{Treatment of separation-related problems}

For owners living with a dog that has separation-related behavior problems, the following instructions may help to reduce or eliminate unwanted behavior in the absence of the owner. Initially, the dog may benefit from the administration of medication such as clomipramine or fluoxetine ${ }^{8,31,45-49}$ administered concurrently with behavior modification. ${ }^{22,53}$ Due to the cost of pharmacological interventions ${ }^{33}$ and their potential adverse side effects, $, 831,48,51$ owners should aim to withdraw medication gradually once the dog's behavior begins to improve. Dog owners should immediately cease all punishment of any dog behavior. ${ }^{20,42-44}$ The most effective behavioral intervention for the treatment of separationrelated problems appears to be a combination of systematic desensitization and counterconditioning. ${ }^{38,56}$ In practice, dog owners should initially leave the dog for very short times, returning almost immediately, and gradually increase the length of their absences. Immediately before the owner's departure, the dog should be given food to create an association between the owner's absence and the positive experience of eating. ${ }^{38,55}$ During this program of behavior modification, owners should avoid long absences, and if behavior worsens, they should reduce the length of their absences again until the dog's behavior improves, before resuming the gradual increase in the length of the absences. Finally, dog owners may find it helpful to place a video recording device in the room where the dog spends the most time in the owner's absence, and monitor the dog's behavior before and during treatment. Dog owners can then establish whether the treatment is, in fact, helping to reduce the problematic behaviors. $^{42}$

\section{Conclusion}

Separation anxiety is a condition that can cause much distress for both owners and their dogs, and can lead to a decision to relinquish dogs. Without appropriate intervention, these dogs may carry their behavioral problems to the next household. ${ }^{19}$ Although the research results do not always agree, there are some factors that may predispose dogs to the development separation-related behavior problems. Owners may be able to prevent the development of canine separation anxiety, but if their dog does develop separation anxiety, the problem may be reduced or eliminated through an owner-administered program of behavior modification, ${ }^{38}$ supplemented in the early stages with medication. $8,22,31,45-49,53$

More research is needed to isolate the factors that are most efficacious in treating canine separation anxiety. It would be helpful to examine the separate effects of systematic desensitization and counterconditioning in the presence and absence of pharmacological interventions to further simplify the advice given to dog owners who are dealing with their dog's separation anxiety.

\section{Disclosure}

The author reports no conflict of interest in this work.

\section{References}

1. Rehn T, Keeling LJ. The effect of time left alone at home on dog welfare. Appl Anim Behav Sci. 2011;29(2-4):129-135.

2. Scaglia E, Cannas S, Minero M, Frank D, Bassi A, Palestrini C. Video analysis of adult dogs when left home alone. J Vet Behav. 2013;8(6):412-417. 
3. Cannas S, Frank D, Minero M, Godbout M, Palestrini C. Puppy behaviour when left home alone: changes during the first few months after adoption. J Vet Behav. 2010;5(2):94-100.

4. Frank D, Minero M, Cannas S, Palestrini C. Puppy behaviours when left home alone: a pilot study. Appl Anim Behav Sci. 2007; 104(1-2):61-70.

5. Blackwell E, Casey RA, Bradshaw JW. Controlled trial of behavioural therapy for separation-related disorders in dogs. Vet Rec. 2006;158(16):551-554.

6. Flannigan G, Dodman NH. Risk factors and behaviors associated with separation anxiety in dogs. $J$ Am Vet Med Assoc. 2001;219(4): 460-466.

7. Gaultier E, Bonnafous L, Bougrat L, Lafont C, Pageat P. Comparison of the efficacy of a synthetic dog-appeasing pheromone with clomipramine for the treatment of separation-related disorders in dogs. Vet Rec. 2005;156(17):533-538.

8. Simpson BS, Landsberg GM, Reisner IR, et al. Effects of reconcile (fluoxetine) chewable tablets plus behaviour management for canine separation anxiety. Vet Ther. 2007;8(1):18-31.

9. Soares GM, Pereira JT, Paixão RL. [Exploratory study of separation anxiety syndrome in apartment dogs]. Ciencia Rural. 2010;40(3): 548-553. Portuguese.

10. Kim YM, Lee JK, Abd el-aty AM, Hwang SH, Lee JH, Lee SM. Efficacy of dog-appeasing pheromone (DAP) for ameliorating separation-related behavioral signs in hospitalized dogs. Can Vet J. 2010;51(4):380-384.

11. Palestrini C, Minero M, Cannas S, Rossi E, Frank D. Video analysis of dogs with separation-related behaviors. Appl Anim Behav Sci. 2010;124(1-2):61-67.

12. Palmer R, Custance D. A counterbalanced version of Ainsworth's Strange Situation Procedure reveals secure-base effects in dog-human relationships. Appl Anim Behav Sci. 2008;109(2-4):306-319.

13. Topál J, Miklósi A, Csányi V, Dóka A. Attachment behaviour in dogs (Canis familiaris): a new application of Ainsworth's (1969) Strange Situation Test. J Comp Psychol. 1998;112(3):219-229.

14. Herron ME, Lord LK, Husseini SE. Effects of preadoption counselling on the prevention of separation anxiety in newly adopted shelter dogs. J Vet Behav. 2014;9(1):13-21.

15. Horwitz DF. Diagnosis and treatment of canine separation anxiety and the use of Clomipramine hydrochloride (clomicalm). J Am Anim Hosp Assoc. 2000;36(2):107-109.

16. Lund JD, Jørgensen MC. Behaviour patterns and time course of activity in dogs with separation problems. Appl Anim Behav Sci. 1999;63(3):219-236.

17. McGreevy PD, Masters AM. Risk factors for separation-related distress and feed-related aggression in dogs: additional findings from a survey of Australian dog owners. Appl Anim Behav Sci. 2008; 109(2-4):320-328.

18. Parthasarathy V, Crowell-Davis SL. Relationship between attachment to owners and separation anxiety in pet dogs (Canis lupus familiaris). J Vet Behav. 2006;1(3):109-120.

19. Stephen J, Ledger R. Relinquishing dog owners' ability to predict behavioural problems in shelter dogs post adoption. Appl Anim Behav Sci. 2007;107(1-2):88-99.

20. Bradshaw J. In Defence of Dogs. Why Dogs Need Our Understanding. London, UK: Penguin Press; 2011.

21. Overall KL. Animal behavior case of the month. A dog was examined because of profound separation anxiety. J Am Vet Med Assoc. 1998;212(11):1702-1704.

22. Sherman BL, Mills DS. Canine anxieties and phobias: an update on separation anxiety and noise aversions. Vet Clin North Am Small Anim Pract. 2008;38(5):1081-1106, vii.

23. Diesel G, Brodbelt D, Pfeiffer DU. Characteristics of relinquished dogs and their owners at 14 rehoming centers in the United Kingdom. J Appl Anim Welf Sci. 2010;13(1):15-30.

24. New JC, Salman MD, Scarlett JM, et al. Moving: characteristics of dogs and cats and those relinquishing them to 12 US animal shelters. $J$ Appl Anim Welf Sci. 1999;2(2):83-95.
25. Takeuchi Y, Ogata N, Houpt KA, Scarlett JM. Differences in background and outcome of three behaviour problems of dogs. Appl Anim Behav Sci. 2001;70(4):297-308.

26. Dreschel NA. The effects of fear and anxiety of health and lifespan in pet dogs. Appl Anim Behav Sci. 2010;125(3-4):157-162.

27. Overall KL, Dunham AE, Frank D. Frequency of nonspecific clinical signs in dogs with separation anxiety, thunderstorm phobia, and noise phobia, alone or in combination. J Am Vet Med Assoc. 2001;219(4):467-473.

28. Blackwell EJ, Bradshaw JWS, Casey RA. Fear responses to noises in domestic dogs: prevalence, risk factors and co-occurrence with other fear related behavior. Appl Anim Behav Sci. 2013;145(1-2):15-25.

29. Riva J, Bondiolotti G, Michelazzi M, Verga M, Carenzi C. Anxiety related behavioural disorders and neurotransmitters in dogs. Appl Anim Behav Sci. 2008;114(1-2):168-181.

30. Bradshaw JW, McPherson JA, Casey RA, Larter S. Aetiology of separation-related behaviour in domestic dogs. Vet Rec. 2002;151(2): 43-46.

31. King JN, Simpson BS, Overall KL, et al. Treatment of separation anxiety in dogs with clomipramine: results from a prospective, randomized, double-blind, placebo-controlled, parallel-group, multicenter clinical trial. Appl Anim Behav Sci. 2000;67(4):255-275.

32. Podberscek AL, Hsu Y, Serpell JA. Evaluation of clomipramine as an adjunct to behavioural therapy in the treatment of separation-related problems in dogs. Vet Rec. 1999;145(13):365-369.

33. Takeuchi Y, Houpt KA, Scarlett JM. Evaluation of treatments for separation anxiety in dogs. J Am Vet Med Assoc. 2000;217(3):342-345.

34. Wright JC, Nesselrote MS. Classification of behaviour problems in dogs: distributions of age, breed, sex and reproductive status. Appl Anim Behav Sci. 1987;19(1-2):169-178.

35. McCrave EA. Diagnostic criteria for separation anxiety in the dog. Vet Clin North Am Small Anim Pract Behav. 1991;21(2):247-255.

36. Pierantoni L, Albertini M, Pirrone F. Prevalence of owner-reported behaviours in dogs separated from the litter at two different ages. Vet Rec. 2011;169(18):468.

37. Schäfer IB, Bartels A, Erhard M. Trennungsangst beim Hund nach Veränderungen im Sozialsystem. Prakt Tierarzt. 2012;93:774-781. German.

38. Butler R, Sargisson RJ, Elliffe D. (2011). The efficacy of systematic desensitization for treating the separation-related problem behaviour of domestic dogs. Appl Anim Behav Sci. 2010;129(2-4):136-145.

39. Schwartz S. Separation anxiety syndrome in dogs and cats. J Am Vet Med Assoc. 2003;222(11):1526-1532.

40. Tuber DS, Miller DD, Caris KA, Halter R, Linden F, Hennessy MB. Dogs in animal shelters: problems, suggestions, and needed expertise. Psychol Sci. 1999;10(5):379-386.

41. Beerda B, Schilder MBH, van Hooff JARAM, de Vries HW. Manifestations of chronic and acute stress in dogs. Appl Anim Behav Sci. 1997;52:307-319.

42. Arhant C, Bubna-Littitz H, Bartels A, Futschik A, Troxler J. Behaviour of smaller and larger dogs: effects of training methods, inconsistency of owner behaviour and level of engagement in activities with the dog. Appl Anim Behav Sci. 2010;123(3-4):131-142.

43. Landsberg G. Diagnosing and treating canine separation anxiety. Paper presented at the 79th Western Veterinary Conference; February 18-22, 2007; Las Vegas, NV.

44. Tuber DS, Hothersall D, Voith VL. Animal clinical psychology: A modest proposal. Am Psychol. 1974;29(10):762-766.

45. Cannas S, Frank D, Minero M, Aspesi A, Benedetti R, Palestrini C. Video analysis of dogs suffering from anxiety when left home alone and treated with clomipramine. J Vet Behav. 2014;9(2):50-57.

46. Ogata N, Dodman NH. The use of clonidine in the treatment of fear-based behavior problems in dogs: an open trial. $J$ Vet Behav. 2011;6(2):130-137.

47. Pineda S, Anzola B, Olivares A, Ibáñez M. Fluoxetine combined with clorazepate dipotassium and behaviour modification for treatment of anxiety-related disorders in dogs. Vet J. 2014;199(3):387-391.

48. Landsberg GM, Melese P, Sherman BL, Neilson JC, Zimmerman A, Clarke TP. Effectiveness of fluoxetine chewable tablets in the treatment of canine separation anxiety. $J$ Vet Behav. 2008;3(1):12-19. 
49. Ibáñez M, Anzola B. Use of fluoxetine, diazepam, and behavior modification as therapy for treatment of anxiety-related disorders in dogs. J Vet Behav. 2009;4(6):223-229.

50. Herron ME, Shofer FS, Reisner IR. Retrospective evaluation of the effects of diazepam in dogs with anxiety-related behavior problems. J Am Vet Med Assoc. 2008;233(9):1420-1424.

51. Kook PH, Kranjc A, Dennler M, Glaus TM. Pancreatitis associated with clomipramine administration in a dog. J Small Anim Pract. 2009;50(2):95-98.

52. Seksel K, Lindeman MJ. Use of clomipramine in treatment of obsessivecompulsive disorder, separation anxiety and noise phobia in dogs: a preliminary, clinical study. Aust Vet J. 2001;79(4):252-256.

53. Appleby D, Pluijmakers J. Separation anxiety in dogs: The function of homeostasis in its development and treatment. Clin Tech Small Anim Pract. 2004;19(4):205-215.
54. Davison GC. Systematic desensitization as a counter-conditioning process. J Abnorm Psychol. 1968;73(2):91-99.

55. Lindsay S. Handbook of Applied Dog Behavior and Training, Volume 3: Procedures and Protocols. Hoboken, NJ: Wiley-Blackwell; 2008.

56. Rogerson J. Canine fears and phobias; a regime for treatment without recourse to drugs. Appl Anim Behav Sci. 1997;52(3-4):291-297.

57. Poppen R. Counterconditioning of conditioned suppression in rats. Psychol Rep. 1970;27:659-671.

58. Wilson GT, Davison GC. Processes of fear reduction in systematic desensitization: animal studies. Psychol Bull. 1971;76(1):1-14.

59. Cottam N, Dodman NH, Moon-Fanelli AA, Patronek GJ. Comparison of remote versus in-person behavioral consultation for treatment of canine separation anxiety. J Appl Anim Welf Sci. 2008;11(1): $28-41$.

\section{Publish your work in this journal}

Veterinary Medicine: Research and Reports is an international, peer-reviewed, open access journal publishing original research, case reports, editorials, reviews and commentaries on all areas of veterinary medicine. The manuscript management system is completely online and includes a very quick and fair peer-review system.
Visit http://www.dovepress.com/testimonials.php to read real quotes from published authors. 